\begin{tabular}{|c|c|c|}
\hline $\begin{array}{l}\text { PKS } \\
\text { PUBLIC } \\
\text { KNOWLEDGE } \\
\text { PROSECT }\end{array}$ & $\begin{array}{c}\text { REVISTA DE GEOGRAFIA } \\
\text { (RECIFE) } \\
\text { http://www.revista.ufpe.br/revistageografia }\end{array}$ & 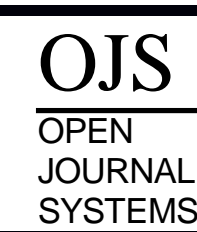 \\
\hline
\end{tabular}

\title{
GEOGRAFIA DA CRIMINALIDADE: O CASO DA TERRITORIALIZAÇÃO DO TRÁFICO DE DROGAS NO BAIRRO DIVINEIA EM SÃO LUÍS/MA
}

\author{
Leandro da Silva Fernandes $1^{1}$ \\ ${ }^{1}$ Geógrafo pela Universidade Federal do Maranhão(UFMA). E-mail: leandroibge@hotmail.com
}

Artigo recebido em 18/06/2017 e aceito em 16/06/2018

\begin{abstract}
RESUMO
Neste trabalho será apresentado o caso particular da territorialização do comércio das drogas, assim como a estruturação das facções em um bairro da capital maranhense, o Divineia. O bairro se origina do processo de crescimento desordenado da capital ocorrido no século XX nas décadas de 70 e 80 , sendo sua ocupação nada pacífica. Para uma abordagem que compreenda de forma crítica a realidade foi adotado como método a dialética. Quanto aos procedimentos metodológicos compreenderam a consulta de autores concernentes ao tema proposto e principalmente de dados originados a partir da pesquisa de campo que envolveram entrevistas com moradores, policiais, informante do tráfico, além de documentação cartográfica e fotográfica. Os resultados mais expressivos elucidaram a vinculação da comercialização dos entorpecentes em escala local com a internacionalização do mercado dos narcóticos. Também foi possível conhecer as áreas de maior disseminação dos alucinógenos, viabilizando uma apresentação detalhada destas áreas com suas peculiaridades e destacando os principais aspectos de atuação dos agentes desse ciclo vicioso.
\end{abstract}

Palavras-chave: Território; Tráfico de Drogas; Comércio.

\section{GEOGRAPHY OF CRIMINALITY: THE CASE OF THE TERRITORIALIZATION OF DRUG TRAFFICKING IN THE DIVINEIA NEIGHBORHOOD IN SÃO LUÍS / MA}

\begin{abstract}
In this paper we will present the particular case of the territorialization of the drug trade, as well as the structuring of the factions in a neighborhood of the Maranhão capital, Divineia. The neighborhood originates from the process of disorderly growth of the capital occurred in the twentieth century in the 70s and 80s, and its occupation is not peaceful. For an approach that comprehends critically the reality was adopted as dialectical method. The methodological procedures included the consultation of authors concerning the proposed theme and mainly data originated from field research that involved interviews with residents, police officers, traffic informants, as well as cartographic and photographic documentation. The most expressive results elucidated the linkage of narcotics commercialization with the internationalization of the narcotics market. It was also possible to know the areas of greatest dissemination of hallucinogens, enabling a detailed presentation of these areas with their peculiarities and highlighting the main aspects of the agents acting in this vicious cycle.
\end{abstract}

Keywords: Territory; Drug Trafficking; Trade. 


\section{INTRODUÇÃO}

A violência urbana é um dos problemas mais complexos da sociedade contemporânea. A gênese, disseminação e consequências desse fenômeno social são o escopo de estudos de diferentes ramos das ciências humanas e sociais, entre eles a Geografia.

Uma das principais faces da violência é a criminalidade, fato sempre recorrente nas grandes cidades no Brasil e em vários países. Segundo Beato Filho (2003) apud Werner (2009) a violência precisa ser entendida e analisada no viés das políticas públicas de segurança, sendo a violência algo amplo envolvendo diversas ações enquanto a criminalidade é uma de suas formas manifestas e reguladas juridicamente.

Quanto aos estudos sobre a criminalidade, segundo Soriano e Guidugli (2009) a primeira corrente científica a estudar a criminalidade em escala espacial foi a Escola Cartográfica de Criminologia do Século XIX, sucedida pela Escola de Chicago nas décadas de 20 e 30 do século pretérito. A Escola Geográfica do Crime vem desde a década de 70 em associação com outros ramos do conhecimento científico à base de teorizações diversas tentando elucidar os problemas que levam a esse fenômeno social. Assim, cabe ressaltar que os estudos relacionados à criminalidade em uma perspectiva geográfica ainda são recentes e precisam ser melhor desenvolvidos e analisados.

Um dos principais representantes em ascensão no século XXI são as organizações criminosas internacionais que se articulam em redes territoriais, facilitadas pelo processo de globalização, não estando apenas restritas às suas próprias matrizes nacionais. O Próprio conceito de "internacional” é preferencialmente na visão de vários autores substituído por “transnacional”. Esta definição acerca da ideia de organização criminosa transnacional indica Werner (2009, p. 52) “O crime organizado transnacional pode ser definido como a associação estratégica de indivíduos que, atuando de forma supranacional, têm por meta a obtenção de um ganho ilícito".

No Brasil a atuação de traficantes tem despertado a atenção, pois cada vez mais estão articulados e cujas ações têm revelado que nem prisões são capazes de impedir o comando das facções por seus líderes. As raízes do tráfico possuem escala macro ou mesmo nas além-fronteiras dificultando articulações mais eficazes das polícias, assim, o crescimento de homicídios e de dependentes seguem em ritmo constante consoante a entrada de drogas ilegais no país, é o que observa Ferreira e Penna (2005) ao exemplificar que no Rio de Janeiro cerca de $99 \%$ (noventa e nove) dos homicídios estão direto ou indiretamente relacionados ao crime organizado. 
No Maranhão, uma das unidades da federação brasileira, a violência atingiu números alarmantes, mas que vieram ao público nacional somente em 2013 com o estopim da morte de 18 detentos na Penitenciária de Pedrinhas, localizada na zona rural de São Luís. O motivo das execuções ocorreu devido à disputa entre duas facções que hodiernamente tentam controlar o tráfico de drogas na capital e no estado.

Segundo Pedrosa (2014) o principal exemplo da articulação territorial em escala nacional do Primeiro Comando da Capital (PCC) está no Maranhão organizado provavelmente entre 2010 e 2011. O Primeiro Comando do Maranhão (PCM) resultou da união dos presidiários vindos do interior do estado, principalmente da Baixada Ocidental Maranhense, e com passagem em presídios de segurança máxima em outras partes do país, aqui se reorganizaram e fizeram frente aos detentos da capital, estes como forma de resposta criaram a facção "Bonde dos Quarenta Ladrões”.

Não custou e veio a intervenção federal com a participação da Força Nacional de Segurança, a resposta das facções semelhante ao que o PCC efetuou em 2006 em São Paulo, foi truculenta com o incêndio de sete ônibus na capital em outubro de 2013. Assim, torna-se imprescindível compreender as implicações das atuações das organizações criminosas em escala local e internacional tendo neste trabalho por base o bairro Divineia localizado em São Luís, considerado um dos mais violentos e vitimados pelo tráfico de entorpecentes na capital.

\section{MÉTODO E METODOLOGIA}

Neste trabalho a pesquisa adotada foi a abordagem qualitativa. Segundo Chizzotti (2005) a abordagem qualitativa parte do fundamento de que há uma relação dinâmica entre o mundo real, o sujeito e o objeto, uma interdependência viva entre o sujeito e o objeto, um vínculo indissociável entre o mundo objetivo e a subjetividade do sujeito. O objeto não é um dado inerte e neutro; está possuído de significados e relações que sujeitos concretos criam em suas ações.

O método para o encaminhamento da pesquisa é o dialético. Segundo Rodrigues e Soares (2009) o materialismo histórico e dialético se funda na premissa de que parte da ciência positiva da história, os indivíduos humanos reais, suas ações e condições de vida, isto é, toda história humana é a existência de indivíduos humanos viventes que por sua vez se distinguem pelos seus meios de vida, que se modificam historicamente e socialmente.

A metodologia aplicada para a obtenção dos dados da pesquisa foram os seguintes: 
Delimitação do espaço e duração da pesquisa: Foi escolhido o bairro Divineia em São Luís/MA, e o período de realização da pesquisa de campo durou entre os meses de abril a outubro de 2015;

Bibliografia: Foram realizadas consultas a materiais diversos como livros, teses, publicações on-line, revistas e comunicações em eventos. Alguns dos autores consultados na linha de pesquisa deste trabalho são Marcelo Lopes de Souza, Ermínia Maricato, Rogério Haesbaert e outros;

Visita técnica a Unidade de Polícia no bairro: Nesta etapa foram realizadas nos dias 28 e 29 de abril entrevistas com quatro militares de diferentes patentes (Sargento, cabo e dois soldados) e ainda o fornecimento de dados referentes à criminalidade no bairro constatados no Relatório Anual 2013/2014 da Unidade de Segurança Comunitária (USC) em conjunto com o Centro Integrado de Operações (CIOPS);

Aplicação de questionários e entrevistas com os moradores do bairro: Foram entrevistados 4 (quatro) moradores mais antigos do bairro a fim de uma melhor compreensão da ocupação do mesmo e maior garantia da assertividade da evolução do tráfico na área de estudo. Entre os entrevistados houve a colaboração imprescindível de um ex-traficante que fora envolvido com as atividades ilícitas das drogas no bairro e elucidou de maneira singular a organização e estrutura das facções que atuam no estado, sendo garantido o sigilo da identidade do entrevistado neste trabalho. Além de que 46 (quarenta e seis) moradores responderam há várias outras questões e que aqui serão apresentadas apenas os resultados mais relevantes ao assunto tratado;

Levantamento cartográfico e registro fotográfico: Será apresentado mapa do bairro estudado e sua localização no estado, assim como imagens obtidas durante a realização do trabalho que caracterizam o assunto abordado.

\section{LOCALIZAÇÃO E URBANIZAÇÃO DO BAIRRO DIVINEIA}

A análise deste estudo abrange em escala local o bairro Divinéia que está situado ao norte da Ilha do Maranhão, distante do centro da capital São Luís a aproximadamente 9 $\mathrm{km}$. A sua área compreende cerca de $1 \mathrm{~km}^{2}$, que equivale a $0,18 \%$ da área da capital de cerca de $834 \mathrm{~km}^{2}$ conforme dados do Censo Demográfico do IBGE em 2010. Está localizado entre as coordenadas geográficas $2^{\circ} 29^{\prime} 40,58^{\prime \prime}$ de latitude Sul e $44^{\circ} 13^{\prime} 10,40^{\prime}$ ' de longitude Oeste (LUCENA, 2013). 
A seguir o mapa do bairro (Figura 1):

Figura 1: Mapa de localização do bairro Divineia.

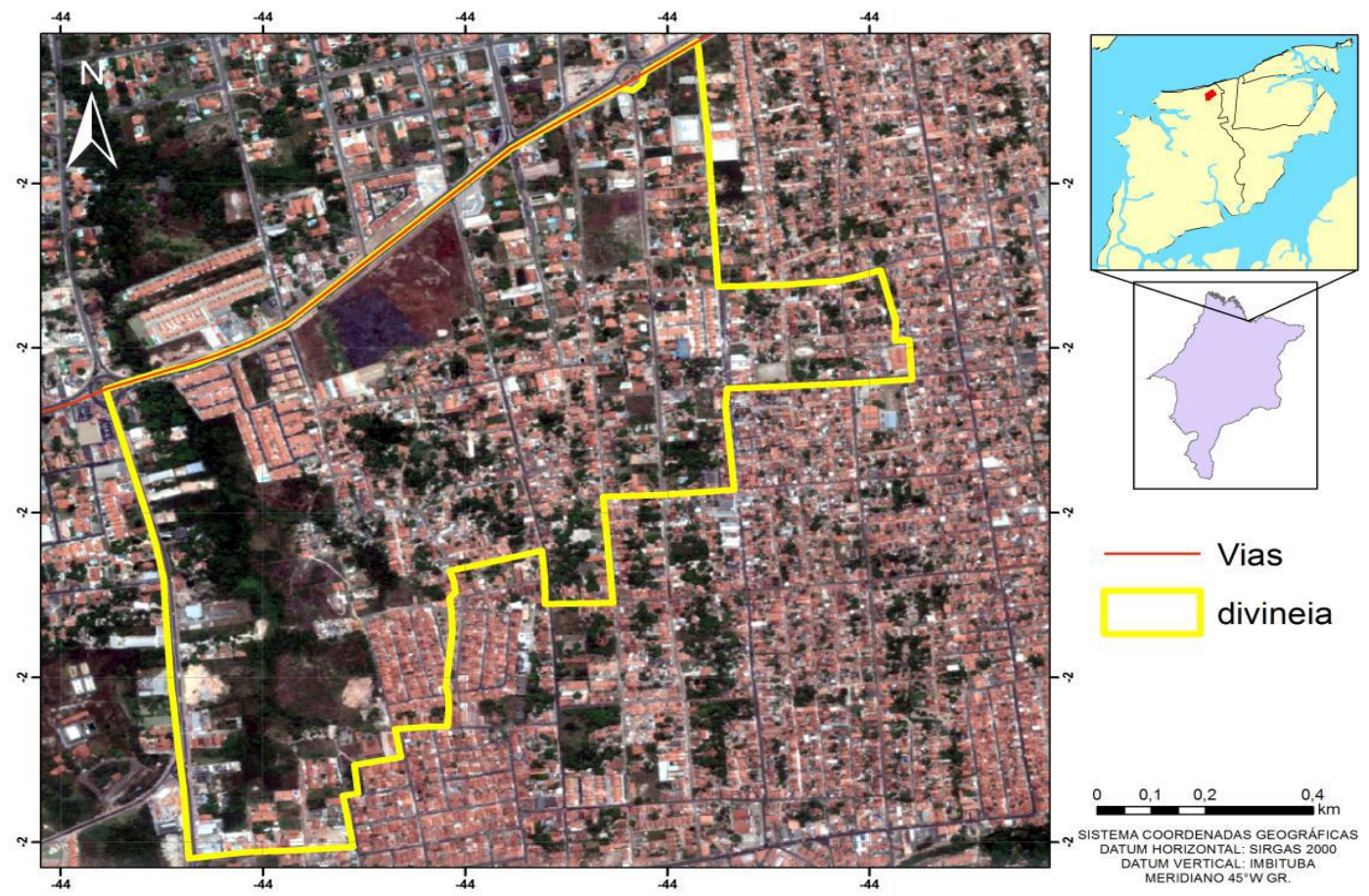

Fonte: Cunha (2014).

O bairro é resultante do processo de ocupação espontânea ocorrida entre as décadas de 70-80 do século pretérito em São Luís, quando o déficit habitacional acelerou a ocupação de terras até então desocupadas por seus donos ou proprietários. Estas ocupações foram designadas de invasão, termo, entretanto que aqui se evitará usar devido a sua não aceitação por parte dos primeiros moradores. Ferreira (2014) elenca 27(vinte e sete) bairros originários desse processo, contemporâneos a ocupação e expansão do Antigo Divinéia e da Nova Divinéia, esta última denominada pela população residente de Vila Litorânea.

Segundo relato dos moradores mais antigos entrevistados, o bairro surgiu em 1973 com a chegada da primeira família e nos primeiros anos foi denominado de Alto da Fome devido às condições precárias dos moradores. As casas eram de taipa, não havia luz elétrica, ruas em forma de veredas sem qualquer saneamento. Conflitos pela posse da terra marcaram os primeiros anos da recém-nascida comunidade. Um fato marcante foi no início da década de 80 quando 450 (quatrocentas e cinquenta) casas foram incendiadas em uma tentativa de reocupação dos supostos donos das terras, levando os moradores a adotarem o nome Divineia em alusão há um bairro de nome igual que fora incendiado na época na novela Saramandaia.

Segundo Carlos (2005, p. 55) "O solo urbano tem valor enquanto produto do trabalho humano [...] Esse valor do solo urbano é produto da articulação da localização do 'terreno urbano' na totalidade da cidade". Assim, se pode inferir que a partir do momento que 
o solo é valorizado haverá aqueles que disputem pela sua posse ou a luta de classes. No caso abordado a articulação dos moradores resultou na criação em 1981 da Associação de Moradores que passaram a enfrentar os problemas e as demandas do bairro, principalmente por condições dignas de serviço e da legalização fundiária.

Segundo Masullo et al 2012 fundamentado em dados do Censo 2010 a Divineia possui 1.669(mil seiscentos e sessenta e nove) domicílios ocupados com média de 3,8 pessoas/domicílios totalizando 6.236(seis mil duzentos e trinta e seis) moradores. Hodiernamente o bairro possui uma boa estrutura no setor de serviços com ampla rede de comércio varejista e feira que abastece os bairros adjacentes, ruas pavimentadas, transporte coletivo e clínicas de saúde bem diferente em relação aos primeiros anos da ocupação, além de que uma das principais reivindicações, a regularização fundiária, está se tornando uma realidade plausível visto que desde 2016 após projeto de ação popular junto ao poder público municipal vários moradores estão recebendo os registros de posse oficial das terras, uma verdadeira conquista da comunidade. Não obstante, há problemas de ordem urgente a serem abordados, entre eles a criminalidade, fato que tem afetado a população com ênfase ao tráfico de drogas que mesmo após a instalação da USC parece não ter solução eficaz e que nesta pesquisa será apresentado de maneira pormenorizado.

\section{A TERRITORIALIZAÇÃO DO TRÁFICO DE DROGAS NO BAIRRO DIVINEIA}

Aqui se discorre acerca de um fenômeno social com implicações de ordem territorial ou socioespacial, neste caso, analisando a sua organização em escala local ou como alguns preferem usar o termo microescala, pois trata da realidade particular de uma coletividade, o bairro, contudo, não se deve esquecer que a organização do tráfico pela viabilidade econômica dos tóxicos não está associada a apenas um fragmento ou parcela do espaço, sendo sua dimensão já antes comentada, vinculada a macroescala ou escala internacional do tráfico de drogas por intermédio de organizações criminosas transnacionais. É o que se pretende demonstrar em particular acerca da estruturação e comercialização dos entorpecentes na Divineia, visto que este problema tem se tornado em um desafio insuperável pela polícia.

A fim de garantir informações mais fidedignas foram levantados dados em entrevistas junto aos moradores que conhecem ou vivem dentro de áreas denominadas de "bocas de fumo", assim como a indicação dos policiais da USC sobre os principais pontos de consumo, além de especialmente neste trabalho contar com a participação imprescindível de 
um ex-traficante e usuário (há quase um ano sem envolvimento com as atividades ilícitas de entorpecentes), profundo conhecedor da realidade atual do tráfico no bairro. Diante das informações prestadas por este em entrevista foi preservada sua identidade original, designado por um termo fictício de informante " $\mathrm{x}$ ".

Inicialmente é preciso elucidar que o entendimento de territorialização ao se referir ao tráfico de drogas deve ser visto em uma perspectiva mais abrangente que o conceito político- jurídico ou estadocêntrico de dominação ou controle. Há certamente uma relação de poder, entretanto o comércio dos tóxicos envolve também relações simbólicas, culturais e principalmente é o resultado de consequências de exclusão social da cidade capitalista. Concordando com a sugestão de Haesbaert (1997, p. 42):

O território envolve sempre, ao mesmo tempo [...], uma dimensão simbólico, cultural, através de uma identidade territorial atribuída pelos grupos sociais como forma de controle simbólico sobre o espaço onde vivem (sendo também uma forma de apropriação), e uma dimensão mais concreta, de caráter político-disciplinar: a apropriação e ordenação do espaço como forma de domínio e disciplinarização dos indivíduos.

Grande parte dos donos ou gerentes de bocas costumam ser pessoas residentes do próprio bairro, onde desenvolvem laços de familiarização com outros moradores e mesmo enquanto "donos" de parcelas fragmentadas de um espaço determinado, mantém uma relação de relativa harmonia com os moradores, agem como simples cidadãos, seus filhos às vezes estão matriculados em escolas da própria comunidade ou até frequentam escolas de níveis bem mais qualificados, contribuem com impostos de energia, água, possuem carros, cumprimentam os moradores e não aceitam alguma desordem, são simples citadinos. Simultaneamente mantém seus negócios muito bem articulados com os olheiros a seu serviço. Vendem diversidades de entorpecentes e tem o seu mercado consumidor garantido, operando no circuito inferior da economia.

Não se pode esquecer que o fortalecimento do tráfico de drogas é face transparente do crescimento da segregação socioespacial, facilmente identificado nas áreas mais excludentes das cidades.

Sem perspectiva de trabalho ou pelo menos à segurança de um trabalho regular; sem estímulo para estudar, discriminada pela cor e pela pobreza; envolvida por uma intensa publicidade que liga felicidade ao padrão de consumo inatingível; participe de uma realidade social desigual e arbitrária além de fetichista, na qual convivem extremos de carências básicas e o consumo conspícuo; submetida a uma relação de favor com os políticos; crescendo em contato com a violência no cotidiano e tendo o crescente aumento das drogas como possibilidade de fuga e eventualmente de ganhos rápidos e fartos, essa é a realidade da imensa massa de jovens que habitam as 
periferias metropolitanas. Com a ausência da cidadania, o terreno é fértil para o desenvolvimento do crime organizado, especialmente através do tráfico de drogas (MARICATO, 1995, p. 45, grifo nosso).

O Bairro Divineia se caracteriza dentro destas condições quanto área fruto de uma ocupação por uma população excluída de outras partes da cidade e que tem sofrido ainda por problemas de ordem sociopolítica sem ou pouca assistência do poder municipal, particularmente a violência tem adquirido maior incidência pela existência do tráfico de drogas em pontos determinados do bairro e indicados pelos moradores pesquisados e pelos policiais entrevistados da USC como os locais mais perigosos do bairro, a seguir (Tabela 1).

\begin{tabular}{|c|c|}
\hline Localidades & Indicação em \% \\
\hline *Rocinha & 20 \\
\hline *Barragem & 11 \\
\hline Todo o bairro & 11 \\
\hline${ }^{*}$ Marrocos & 8 \\
\hline Morro do Urubu & 5 \\
\hline Outras localidades e pontos & 39 \\
\hline Não há locais perigosos & 6 \\
\hline \multicolumn{2}{|c|}{$\begin{array}{l}\text { Obs. As localidades que possuem asterisco (Rocinha, Barragem e Marrocos) foram } \\
\text { indicadas como de circulação de drogas e outras ações criminosas, não somente } \\
\text { por moradores como também por policiais e informante do tráfico no bairro. }\end{array}$} \\
\hline
\end{tabular}

Fonte: Dados da Pesquisa (2015).

Muitas das áreas indicadas como pontos perigosos lembram ou carregam até nomes que fazem alusão as favelas cariocas, como Rocinha e Cidade de Deus, ainda que em suas formas topográficas tipifiquem algo semelhante, entretanto com distinções de tamanho e diferenças em relação à realidade dos moradores cariocas. Alguns outros pontos além daqueles que aparecem com nomes designados na Tabela 1(um) também são localidades onde há bocas: Cidade de Deus, Vila Bacuri, Vila Vitória, Vila São José, Vila Sapinho e Rua Jerusalém.

Relevante são aqueles que acreditam que todo o bairro é perigoso, o que é um possível indicativo de uma fobia a todo o lugar ou "bairrofobia", um sentimento inverso a "bairrofilia", consequências diretas do medo generalizado em decorrência da violência urbana e da desconstrução socioespacial que esse problema pode causar. A seguir é apresentado o Gráfico 1 (um) fornecido pela USC do bairro que ratifica o tráfico de narcóticos como um dos principais aspectos da criminalidade. 
Gráfico 1: Material apreendido, encontrado, recolhido, removido em 2013 (3.092 apreensões)

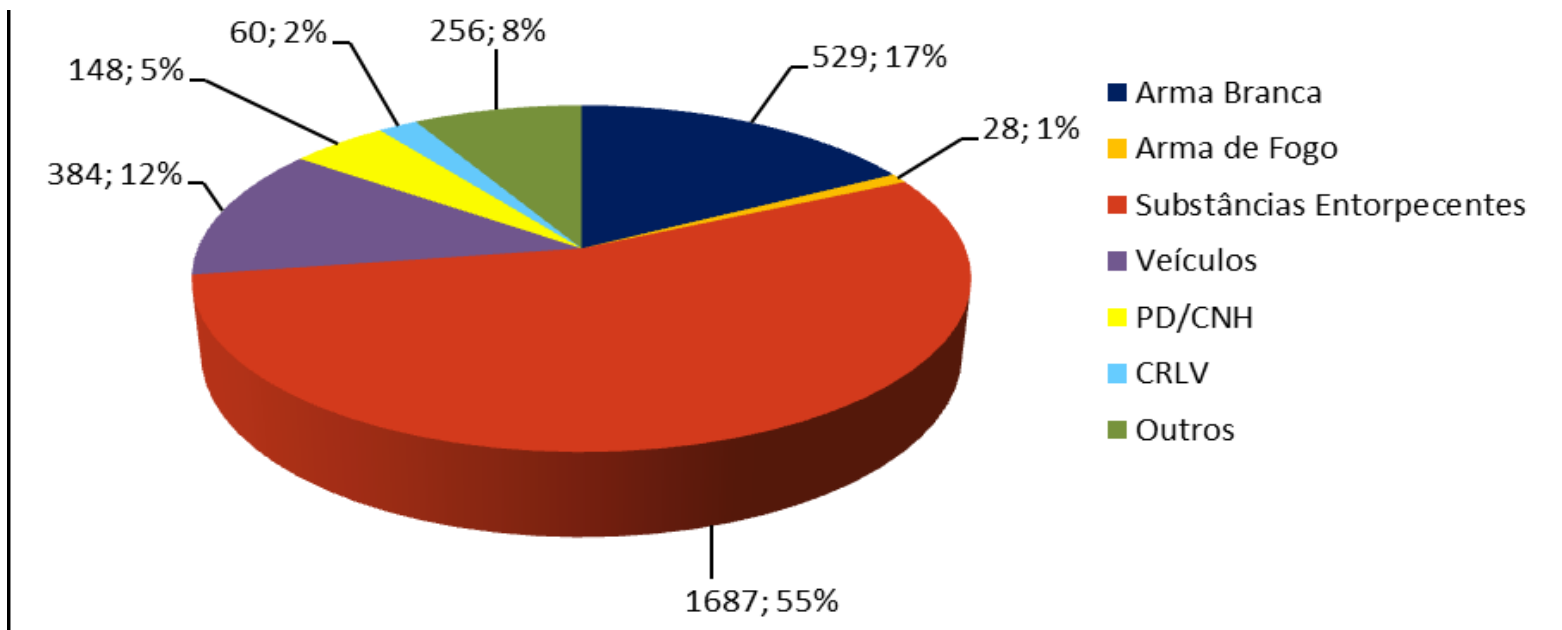

Fonte: Seção Operacional da $1^{\mathrm{a}}$ USC (2013).

O Relatório Anual 2013-2014 da USC Divineia indica como um dos principais pontos críticos do bairro a topografia do terreno que possui arruamentos irregulares e estreitos. Aponta o tráfico de entorpecentes como um dos principais crimes da realidade socioespacial do bairro. O tráfico de drogas correspondeu praticamente à maioria das apreensões durante o ano de 2013 o que somente ratifica a urgência do problema que se apresenta cada vez mais semelhante a um flagelo caudal imbricado profundamente nas contradições urbanas, supera em muito o segundo número de apreensões que são armas brancas costumeiramente usadas por delinquentes em pequenos roubos.

A seguir serão focadas as três localidades que adquiriram maior relevância nesta pesquisa (Rocinha, Barragem e Marrocos), não obstante, desde já é necessário considerar que aqui não se pretende impregnar rótulos a estas áreas ou aprofundar ainda mais um sentimento de medo que comumente vem sobrecarregado de preconceitos e muitas distorções acerca dos residentes destas localidades, uma vez que a grande maioria não é envolvida ou cúmplice das atividades ilícitas das drogas, tão somente se procura apresentar de modo mais concreto a realidade de um flagelo social que afeta a territorialidade dos moradores de um bairro da capital.

PRINCIPAIS ÁREAS DO TRÁFICO DE DROGAS NO BAIRRO Vila Marrocos

Situada entre o cruzamento das Ruas Colômbia e Jaú no bairro Divineia, a Vila Marrocos surge como uma das áreas de ocupações recentes em 1998. Segundo a moradora 
$\mathrm{Isa}^{1}$ que reside no Marrocos, o nome foi dado por uma mulher sem certeza de qual relação tenha sido feita com a origem do lugar. A moradora acredita em duas possibilidades, uma seja a adoção do nome em alusão ao país africano Marrocos, a outra seria devido à proximidade com ruas do bairro que comumente recebem nomes de países como Colômbia e Bolívia.

No início da ocupação da vila não havia tantos casos de criminalidade, segundo relata a própria moradora, todavia o número de pessoas chegando se intensificou e dentre estas a chegada de uma moradora conhecida como "dona Rosa", doravante instalou-se um ponto de venda de drogas.

Essa residente vendia drogas diariamente e isso tornava a ocupação frequentada por várias pessoas que vinham de outros lugares para comprar, eram senhores e até mesmo pessoas chegavam em carros, muita gente que ninguém na vila havia visto anteriormente (informação verbal ${ }^{2}$ ).

A seguir imagens da Vila Marrocos (Figuras 2 e 3):

Figuras 2 e 3: Ruas estreitas em Vila Marrocos. Na figura 2 já funcionou uma boca.

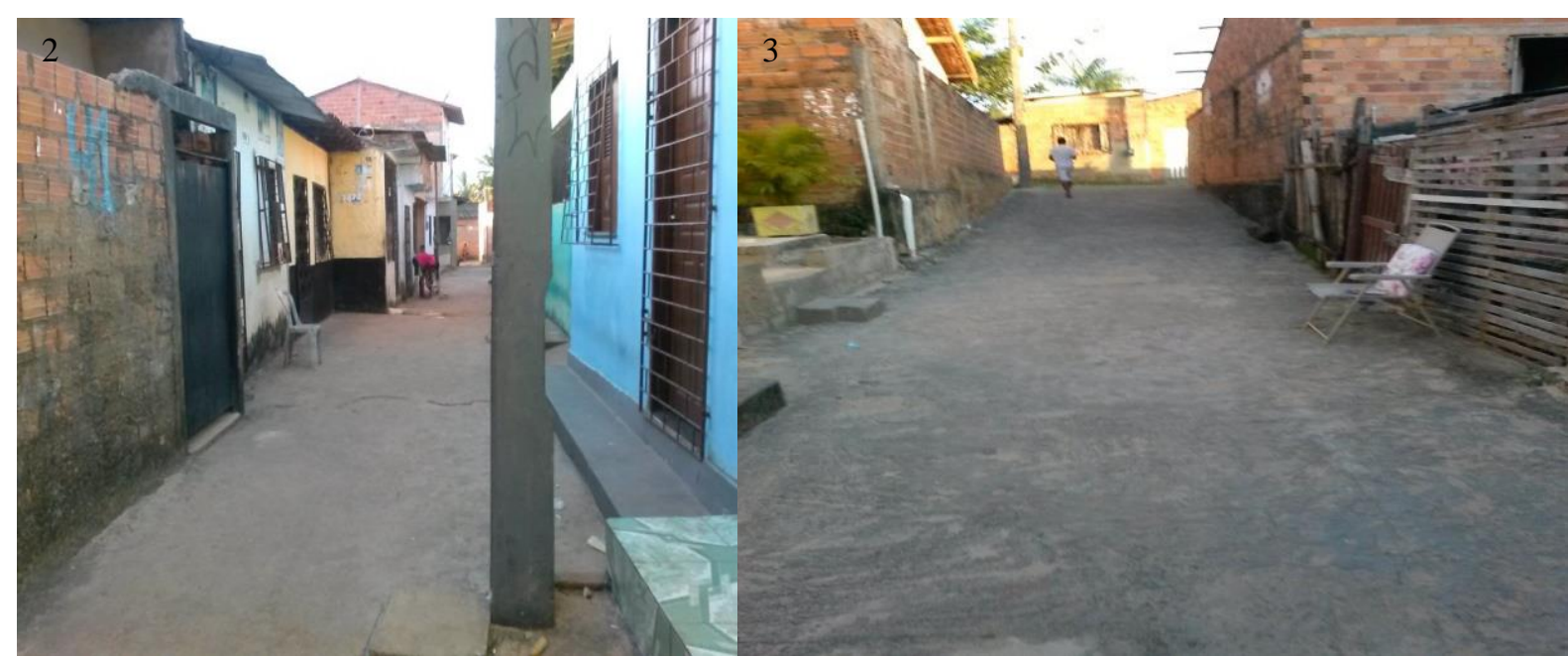

Fonte: Dados da Pesquisa (2015).

A moradora relata que a traficante era conturbada, se envolveu em uma briga com a mãe dela, contudo sem maiores consequências. Isso tornava a localidade como uma das mais conhecidas em termos de tráfico de entorpecentes, cuja ação dos vândalos chegou a desafiar policiais e facções rivais como o PCM, divulgadas em um funk feito pelos traficantes das várias bocas da Divineia, observe a reportagem a seguir:

Não se fala em outra coisa na região da Divinéia e Vila Luizão. Os homens que comandam o tráfico de drogas na área passaram de todos os limites e agora

\footnotetext{
${ }^{1}$ Isa é moradora da Vila Marrocos há treze anos e tem 34 anos de idade. Entrevista concedida em 08/07/2015.

${ }^{2}$ Informação prestada pela moradora Isa residente da Vila Marrocos.
} 
distribuem clandestinamente um funk produzido e gravado por eles mesmos, no qual exaltam seus feitos criminosos e afrontam a polícia. $\mathrm{Na}$ Vila Luizão funciona a primeira Unidade de Segurança Cidadã (USC) construída pelo Governo do Estado. Mas nem isso tem intimidado os bandidos. Segundo apurou o blog, o funk de certo Bonde do Sapinho espalhou-se pela comunidade de mão em mão, sendo compartilhada simplesmente por meio de celulares. Nos bares das redondezas já é comum ouvir a canção que fala em 'caçadores de alemão' ou de 'PCM' denominação do tráfico para os policiais e para o Primeiro Comando do Maranhão, facção rival e no uso de menores portando pistolas calibre 40. A música cita ainda os carros nos quais os traficantes trafegam pela comunidade - Megane, Citroën, Capitva e Hilux - revela alguns nomes e até as bocas de fumo mais famosas do setor, como Marrocos e Babado Novo. 'Se entrar na Divinéia, a bala vai cantar', diz outro trecho. (LEDA, em 23 de julho de 2013, grifo nosso).

A manifestação simbólica do poder dos traficantes no bairro é realizada através de armas e carros e até de música. Uma forma de demonstrar a importância que eles têm é utilizarem-se dos meios de consumo que o sistema capitalista os impossibilitou por outro modo. Hodiernamente o tráfico de drogas na Vila Marrocos ainda existe, mas em pouca intensidade, visto que este não é um problema que se soluciona com rapidez, pois suas causas de reprodução estão muita mais associadas a um ciclo vicioso, que tem tentáculos em praticamente todo o país e encontra nas classes mais vulneráveis um fértil solo ao desenvolvimento de seus flagelos ao oferecer um caminho alternativo de lucro e vida próspera de modo fácil.

\section{Barragem}

O nome muito provavelmente se origina da existência de uma declividade ou um pequeno morro, chamado pelos moradores de barra que dificultava a entrada na área nos primeiros anos da ocupação, hoje limitada a apenas uma rede de esgotos e um pequeno rio. A forte presença de uma boca de fumo protegida por "verdadeiros soldados armados de facas, paus e armas de fogo", facilitada pelas dificuldades de acesso ao terreno, viabilizaram a essa porção do bairro a fama de gangues que praticamente recorrem à década de 80 do século pretérito e se perpetuaram de alguma forma com maior contundência na primeira década do presente século.

Os grupos adotavam nomes que impusessem respeito aos moradores e temor aos rivais, entre alguns desses grupos se destacaram cada um há seu tempo, a OTB (Os Terroristas da Barragem), AIV (esta sem conhecer o real significado do nome), e a Bota Preta. As rivais desses grupos eram gangues que pertenciam ou atuavam em bairros adjacentes como Sol e Mar e Vila Luizão. Há aqui um sentido de territorialidade das gangues, 
comumente formadas por jovens do próprio bairro, estes criam verdadeiros "guetos" com suas ordens disciplinares conforme Maricato (1995, p. 32):

Não é de se estranhar que em tais situações pode ocorrer o desenvolvimento de normas, comportamentos, mecanismos, procedimentos extralegais que são impostos à comunidade pela violência ou que são aceitos espontaneamente e até desejados.

O jovem da favela ou da periferia entendida no sentido mais informal por não ter recursos que viabilizem seu acesso a bens de consumo ou mesmo a manutenção de uma vida digna acaba observando no tráfico um escape e maneira de obter tudo que a sociedade capitalista lhe impediu de desfrutar. Apesar de com a instalação da USC, quando muitos dos membros das gangues, inclusive seus líderes, foram capturados havendo poucos deles hodiernamente, a comercialização de entorpecentes e de armas continua ocorrendo e se recria sempre com novos agentes e gente disposta a pagar e consequências nefastas na barragem continuam ganhando as páginas dos jornais.

\section{Rocinha}

Esta foi indicada pela maioria dos pesquisados como localidade de intensa comercialização de entorpecentes, fato verificado durante a pesquisa em campo. A rocinha já recebeu outros nomes como Vila Fumaça e Vila Maconha cujos nomes já propõem acerca do que se trata sendo a atual denominação a mais aceita por alguma alusão a favela da Rocinha no Rio de Janeiro. A área analisada possui uma rede de pequenos becos que dificultam a entrada de veículos e pessoas desconhecidas, ainda que haja relativa harmonia da boca com os moradores do bairro. A seguir imagens da localidade citada (Figuras 4 e 5): 
Figuras 4 e 5: Rua estreita (4) e beco (5) utilizados na via do tráfico na Rocinha.

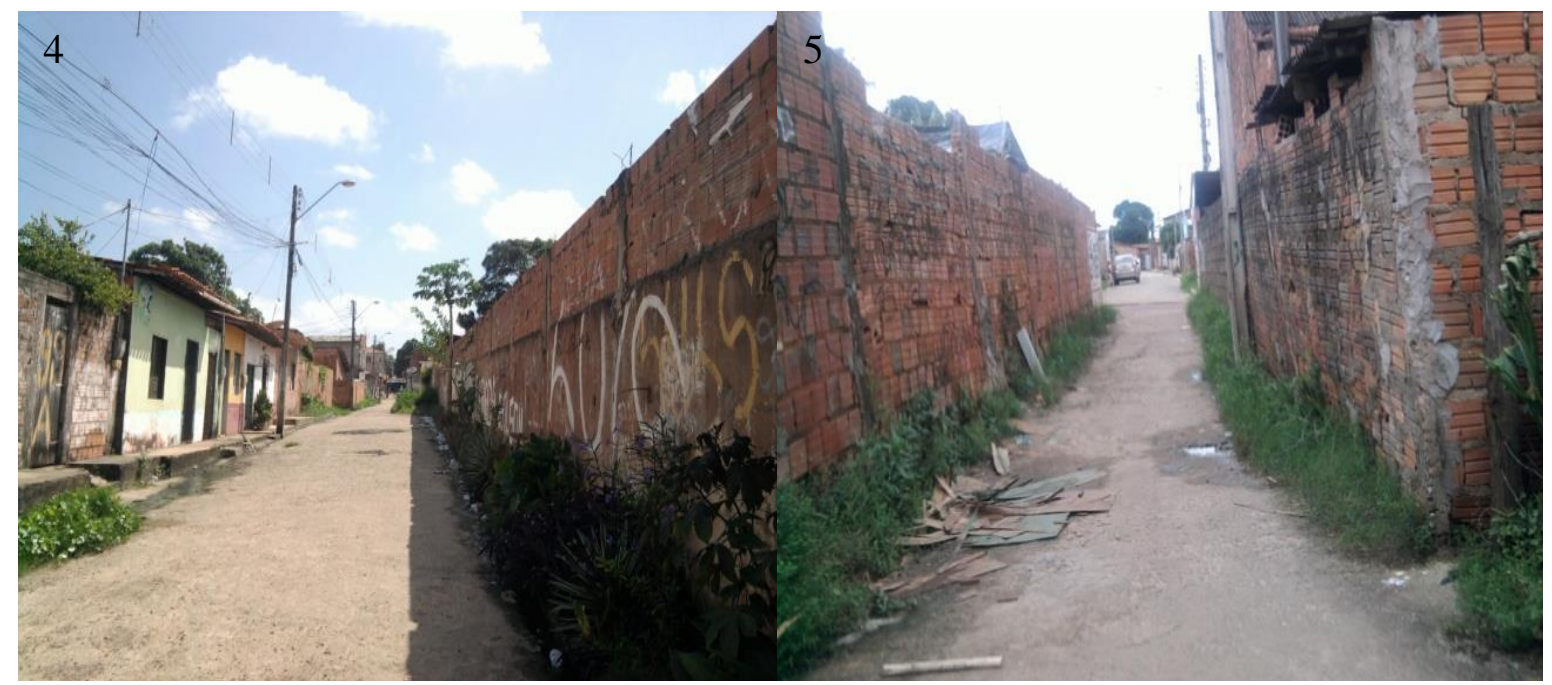

Fonte: Dados da Pesquisa (2015).

A fim de entender melhor a comercialização das drogas neste local e de alguma maneira o funcionamento e organização do tráfico no bairro, foram consultadas as informações de um ex-traficante e usuário que conviveu cerca de oito anos com os esquemas e atividades ilícitas na Boca da Rocinha e em outros pontos de comercialização dos alucinógenos no bairro.

Segundo o informante $\mathrm{x}^{3}$ a grande maioria das pessoas que se envolvem com o submundo dos alucinógenos internalizam em si fetiches de superioridade em relação aos demais e procuram meios, alternativas de satisfação a essa utopia. São ideias de alguma maneira disseminadas socialmente como "não ter limites", "tem que ser homem", ou seja, moralidades como o "machismo" e outras entendidas com efeitos ao extremo reflexo do imposicionismo dos preceitos capitalistas.

Entre as drogas comercializadas no bairro estão: o crack, a maconha e o tof, estas são as mais vendidas, há também a cocaína, o ecstasy e a oxi. A oxi é derivada da pasta de cocaína enquanto o tof é derivado da maconha que é prensada e tem uma substância química capaz de tornar a pessoa dependente do narcótico de modo mais rápido e efeito de duração mais prolongado. O preço varia conforme o tipo, tamanho ou quantidade que é requerida pelo comprador, segundo o informante $\mathrm{x}$ :

\footnotetext{
3 As informações foram prestadas por um homem de 33 anos, morador do bairro há 20 anos e que está se recuperando a quase um ano do envolvimento com o tráfico de drogas, a fim de manter o sigilo de sua identidade foi adotado como sugestão de termo fictício “informante x". Entrevista concedida em 9/10/2015.
} 
É por tamanho, tem a quantidade de cinco reais, aí vai, têm às vezes eles vendem de sopa, aí eles confirma a quantidade, há! Quero tanto!, Aí vai e faz ou então tem a de uma grama que é um valor, aí vai aumentando, tamanho e quantidade vai aumentando o valor. Sempre é a quantidade de $\mathrm{R} \$ 5,00$, que é a pedra (grifo nosso).

Essa forma de comercialização se caracteriza consoante Souza (2008) de subsistema varejo, qualificado pela venda em locais determinados em favelas e bairros, ou seja, é o ponto final e de contato com o consumidor, o usuário, e semelhante ao varejo de produtos que dispõem de variedades e preços, assim se assemelha a aquisição dos narcóticos. No caso da Divineia esses pontos estão concentrados nas bocas de fumo, nestas há "gerentes" ou os responsáveis pelo funcionamento dos pontos, os gerentes possuem "olheiros", que distribuem os produtos (entorpecentes) àqueles que compram, nesta atividade muitos participam conforme afirma o informante x: "Todo mundo participa, sô não criança de dez pra baixo, mas, digamos de doze anos pra frente já tão traficando, já tão usando".

O usuário comumente já é reconhecido de longe e como forma de comunicação eles fazem gestos e sinais, quando há falta do produto usam expressões que fazem alusão a algum tipo de narcótico, um exemplo "faltou óleo na minha casa", concerne ao crack e a falta de estoque desta substância. Se alguém não pagasse o que devia ou não estivesse segundo as disciplinas do grupo sofreria uma "casinha", que se refere a uma emboscada a fim de executar o devedor ou infligidor. Tudo isso são formas peculiares que o mercado do tráfico possui no bairro.

Os principais locais de origem dos materiais que servem a produção das drogas na Rocinha no Divinéia são o Paraguai e o Pará, este último muito provavelmente seja o corredor dos narcóticos de cocaína oriundos da Colômbia e do Peru. Assim foi possível elaborar um esquema da circulação internacional da maconha até o bairro, a seguir (Figura 6). 
Figura 6: Esquema da circulação da maconha entre o Paraguai e a Rocinha.

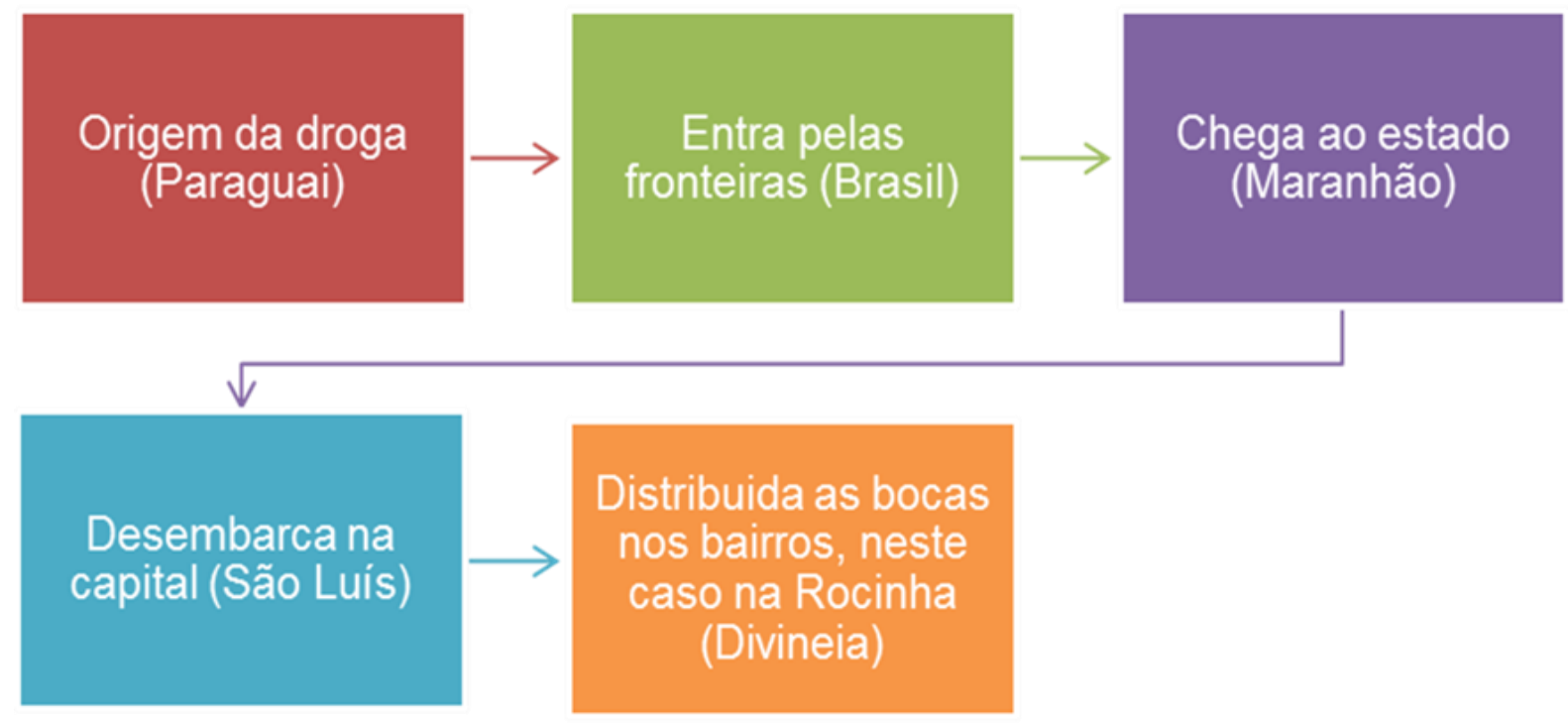

Fonte: Dados da Pesquisa (2015).

Observando o esquema da circulação da droga se pode concluir que além do varejo de entorpecentes no bairro, os principais fornecedores estão em níveis e escalas acima da simples escala local ou quanto a sua organização concorda com a colocação de Souza (2008) ser este o subsistema Importação/Exportação/Atacado. No caso da Divineia, a pedra do narcótico é importada de outro país (Paraguai (maconha), Colômbia ou Peru (cocaína)), segue pela região Centro-Oeste (Mato Grosso do Sul) ou pela região Norte (Amazonas, com ênfase ao Pará) através das embarcações até chegarem a comboios de caminhão, ônibus ou mesmo carros ao Maranhão com maior destino a abastecer as bocas em várias partes da capital, estando compreendida a Rocinha no bairro. Isso permite também inferir que o bairro está praticamente situado dentro da rota do tráfico internacional sendo apenas uma diminuta parcela ou núcleo dessa rede articulada em escala internacional. É neste subsistema Importação/Exportação/Atacado (IEA) que estão os verdadeiros chefes do tráfico.

Hodiernamente não há mais gangues organizadas como outrora, a exemplo do que ocorria na Barragem, não obstante o esquema tornou-se muito mais articulado e estruturado. Se anteriormente se podia falar em gangues com disciplinas normativas e forte sentido de territorialidade relacionada às parcelas dos bairros sendo elas uma forma de representação única e peculiar às localidades, agora a organização do tráfico está vinculada a uma facção que não obedece a limites fisiográficos, agregando diversas bocas em pontos diferentes da capital, observe o esquema a seguir (Figura 7): 
Figura 7: Estrutura hierárquica em rede de facção que atua sobre a Rocinha.

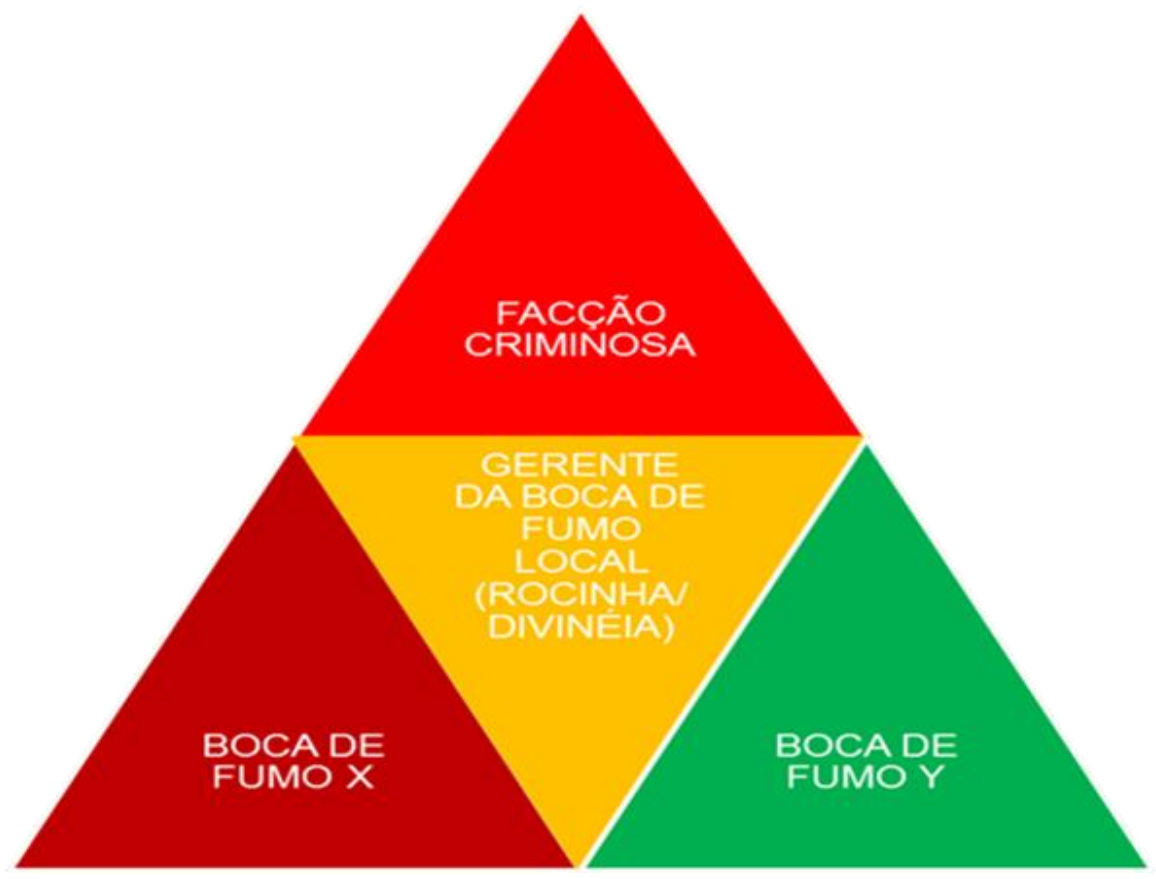

Fonte: Dados da Pesquisa (2015).

De acordo com a pirâmide relacional há uma organização em rede do tráfico que atua em diferentes bairros da cidade, cujas bocas de fumo são subfiliadas a uma matriz principal, uma facção representada no ápice da pirâmide, de onde partem as ordens e que devem ser obedecidas. Não são permitidos conflitos entre as bocas que pertençam à mesma facção, nesta nova situação, o dono de uma boca já não é visto como o superior absoluto, apenas um gerente de um negócio local a qual presta serviço a uma entidade maior, é o que fica evidente no depoimento do informante $\mathrm{x}$ quando indagado sobre as rivalidades entre gerentes de bocas distintas.

Essa é a atual característica das organizações criminosas que aprenderam a trabalhar em forma descentralizada, semelhante às organizações criminosas transnacionais, diferenciadas pelo antigo regime sob disciplina de um líder único - no caso as gangues - e limitadas a um território determinado, doravante possuem comandos com vários núcleos em partes distintas e mais abrangentes, dificultando a identificação ou prisão de seus principais coringas. 


\section{CONSIDERAÇÕES FINAIS}

Nesta pesquisa foram apresentados dados e informações tanto de fontes primárias quanto de fontes secundárias na tentativa de elucidar e compreender em uma perspectiva ampla a disseminação do tráfico de drogas em uma parcela de um território. Contudo, cabe ressaltar que aqui não se pretendeu esgotar tal assunto sendo reconhecidamente um problema de ordem social complexo e em tão poucas páginas seria inviável abordar por completo a amplitude desse fenômeno.

Cabe relevar que as características de organização e estruturação do tráfico de drogas aqui analisados buscaram de maneira focada interpretá-los a luz de um viés geoespacial ou geográfico o que permitiu com sucesso elucidar as dimensões de um problema local vinculado a um processo de estruturação em escala internacional. De maneira direta ficou comprovada que a atual conjuntura de comercialização dos alucinógenos atingiu em São Luís uma escala de ciclo integrada ao tráfico transnacional das organizações criminosas, assim como é possível afirmar que as estruturas de tais facções estão bem articuladas em termos de geoestratégia superando a escala de atuação das polícias, o que sugere desde já uma integração mais participativa dos órgãos de investigação nas esferas municipal, estadual e federal.

Ainda que não se possa inferir qualquer relação de áreas de ocupação desordenada caracterizadas por populações de baixo poder aquisitivo com a criminalidade, contudo não se pode negar que o tráfico em sua hodierna conjuntura encontra solo fértil a sua disseminação ao ser visto como escape e caminho viável ao mundo do consumo capitalista. Cumpri dizer que conforme a realidade exposta por meio do caso do bairro Divineia, é a própria ocupação desordenada resultado da reprodução desigual da cidade capitalista e o circuito inferior da economia como o mercado dos entorpecentes, a vertente mais abissal desse sistema.

Nesta pesquisa foi adotado como categoria de estudo o território, uma vez que tal tema se constitui como uma das bases de fundação da Geografia. Exatamente pela noção de poder que compõem essa categoria foi considerada a atuação das organizações do tráfico de entorpecentes sobre uma realidade da parcela de um espaço, o bairro, não estando este estudo limitado à visão estadocêntrica. Ao detalhar a atuação dos traficantes no Divineia se buscou mostrar que essa comercialização possui modos e maneiras particulares com símbolos e regras, ou seja, um mundo, uma territorialidade própria.

Cumpri considerar que na realização deste trabalho houve apoio imprescindível de moradores e até mesmo o acompanhamento de uma Agente Comunitária da Saúde que 
viabilizou no acesso as áreas de maior periculosidade possibilitando a documentação fotográfica de pontos específicos do tráfico, e da corroboração da Polícia Militar do Maranhão instalada no bairro, apoios que viabilizaram no sucesso desta pesquisa, além da dificuldade de entrevista com cooperador que fora envolvido no tráfico local cujas informações foram extremamente relevantes para obtenção fidedigna da articulação do comércio das drogas em escalas local e transnacional. Portanto, as soluções viáveis para redução de problemas dessa ordem passam por questões sociais cruciais como a realização de projetos populares pensados pela comunidade junto às autoridades governamentais, uma construção pensada com a população como melhoria da qualidade de vida e dos serviços públicos prestados, inclusive na capacitação educacional e profissional de adolescentes e jovens e assistência social a famílias afetadas pelas drogas, assim a condição socioespacial seria mais bem estruturada.

\section{REFERÊNCIAS}

CARLOS, Ana Fani Alessandri. A Cidade: O homem e a cidade A cidade e o cidadão De Quem é o Solo Urbano?. 8 ed. São Paulo: Contexto, 2005.

CHIZZ0TTI, Antonio. Pesquisa em Ciências humanas e Sociais. 7. ed. - São Paulo: Cortez, 2005 .

CUNHA, Caroline Silva. Mazelas do Urbano: Impactos Socioambientais decorrentes da Ocupação Espontânea no Bairro Divineia. São Luís-MA. Monografia apresentada ao curso de Geografia da Universidade Federal do Maranhão, 2014.

FERREIRA, Antônio José de Araújo. A Produção do Espaço Urbano em São Luís do Maranhão: passado e presente; há futuro?. São Luís: EDUFMA, 2014.

FERREIRA, Ignez Costa Barbosa; PENNA, Nelba Azeba. Território da Violência: um olhar geográfico sobre a violência urbana. GEOUSP, São Paulo, n. 18, p. 155 - 168, 2005.

HAESBAERT, Rogério. Des-Territorialização e Identidade: a rede gaúcha no Nordeste. Niterói, RJ: EDUFF, 1997.

INSTITUTO BRASILEIRO DE GEOGRAFIA E ESTATÍSTICA. Censo Demográfico 2010. Rio de Janeiro. Disponível em: 〈http://www.ibge.gov.br>. Acesso em: 12 jan. 2014. LEDA, Gilberto. Em São Luís, traficantes produzem funk para afrontar a polícia. Blog do Gilberto Leda, São Luís, 22 jul 2013. Disponível em: 〈http://www.gilbertoleda.com.br〉. Acesso em: 5 abr 2015. 
LUCENA, Luciano Farias. O Processo de Segregação Socio-espacial de São Luís-MA e suas Implicações: O caso do Bairro Divineia. Monografia apresentada ao curso de Geografia da Universidade Federal do Maranhão, 2013.

MARICATO, Ermínia. Metrópole na Periferia do Capitalismo. Ilegalidade, Desigualdade e Violência. São Paulo: HUCITEC, 1995.

MASULLO, Yata Anderson Gonzaga; NASCIMENTO, Talita de Sousa; CARVALHO, Dionatan Silva. Desenvolvimento Desigual e a Produção do Espaço no Município de São Luís-MA. São Luís: INSTITUTO MARANHENSE DE ESTUDOS SOCIOECONÔMICOS E CARTOGRÁFICOS/IMESC, 2012.

PEDROSA, Luís Antônio Câmara. Complexo Penitenciário de Pedrinhas: do seletivismo penal ao cadafalso. In: SOCIEDADE MARANHENSE DE DIREITOS HUMANOS. Catirina. São Luís: SMDH, 2014.

RODRIGUES, Isabela Soares; SOARES, Jefferson Justino (2009). Influência do materialismo histórico e dialético na Geografia: Debates acadêmicos e suas perspectivas para a Educação Básica. $10^{\circ}$ Encontro Nacional de Prática do Ensino da Geografia-ENPEG: UERJ, comunicação oral.

SORIANO, Érico; GUIDUGLI, Odeibler Santo. Criminalidade e medo: suas relações com as mudanças geográficas nas áreas urbanas. In: ORTIGOZA, Silvia Aparecida Guarnieri; GERARDI, Lucia Helena de Oliveira (Orgs.). Temas da Geografia Contemporânea. Rio Claro-SP: UNESP/IGCE: AGETEO, 2009.

SOUZA, Marcelo José Lopes. As drogas e a "questão urbana" no Brasil. A dinâmica sócioespacial nas cidades brasileiras sob a influência do tráfico de tóxicos. In: CASTRO, Iná Elias de; GOMES, Paulo Cesar da Costa; CORRÊA, Roberto Lobato (Orgs.). Brasil: Questões Atuais da Reorganização do Território. 5 ed. Rio de Janeiro: BERTRAND, 2008.

UNIDADE DE SEGURANÇA COMUNITÁRIA. Relatório Anual 1 USC-2013. São LuísMA: Secretaria de Estado da Segurança Pública, 2014.

WERNER, Guilherme Cunha. O Crime Organizado Transnacional e As Redes Criminosas. 2009, 241 f. Tese de Doutorado (Doutorado em Ciência Política) - Faculdade de Filosofia, Letras e Ciências Humanas da Universidade de São Paulo, São Paulo, 2009. 